Disclosure of Interests: Khojasta Talash: None declared, Marwan Bukhari Speakers bureau: Bristol-Myers Squib, UCB celltech, Roche/Chugai, Pfizer, Abbvie, Merck, Mennarini, Sanofi-aventis, Eli-Lilly, Janssen and Novartis. DOI: 10.1136/annrheumdis-2019-eular.900

\section{SAT0247 FEMALE SEX AND AGE AT DIAGNOSIS ARE ASSOCIATED WITH A DECREASED POSSIBILITY OF DRUG DISCONTINUATION IN GIANT CELL ARTERITIS: DATA FROM A MULTICENTER PROSPECTIVE COHORT OF 177 PATIENTS}

Christina Tsalapaki ${ }^{1}$, Argyro Lazarini ${ }^{1}$, Maria Tektonidou ${ }^{2}$, Petros Sfikakis ${ }^{2}$, Vasiliki Dania ${ }^{3}$, Kyriaki Boki ${ }^{3}$, Evripidis Kaltsonoudis ${ }^{4}$, Paraskevi V. Voulgari ${ }^{4}$, Gerasimos Evangelatos ${ }^{5}$, Alexios lliopoulos ${ }^{5}$, Evangelos Theotikos ${ }^{6}$, Antonia Elezoglou ${ }^{6}$. Charalampos Papagoras ${ }^{7}$, Theodoros Dimitroulas ${ }^{8}$, Alexandros Garyfallos ${ }^{8}$, Dimitrios Boumpas ${ }^{9}$, Georgios Vosvotekas $^{10}$, Dimitrios Vassilopoulos'. ${ }^{1}$ Joint Rheumatology Program, Clinical ImmunologyRheumatology Unit, 2nd Department of Medicine and Laboratory, University of Athens, School of Medicine, Athens, Greece; ${ }^{2}$ Joint Rheumatology Program, First Department of Propedeutic Internal Medicine, University of Athens, School of Medicine, Athens, Greece; ${ }^{3}$ Sismanoglio Hospital, Rheumatology Unit, Athens, Greece; ${ }^{4}$ Rheumatology Clinic, University of loannina, loannina, Greece; ${ }^{5}$ NIMTS Hospital, Rheumatology Unit, Athens, Greece; ${ }^{6}$ Asklipiion General Hospital, Rheumatology Unit, Athens, Greece; ${ }^{7}$ Democritus University of Thrace, Rheumatology Clinic, Thrace, Greece; ${ }^{8}$ Aristotle University, 4th Department of Medicine, Thessaloniki, Greece; ${ }^{9}$ Joint Rheumatology Program,4th Department of Medicine, Attikon Hospital, University of Athens, School of Medicine, Athens, Greece; ${ }^{10}$ Private Practice, Thessaloniki, Greece

Background: Giant cell arteritis (GCA) usually requires long-term therapy with corticosteroids and/or Disease Modifying Anti-rheumatic Drugs (DMARDs) but the exact factors that are associated with drug discontinuation in these patients have not been well defined.

Objectives: To evaluate the baseline or on-treatment factors that influence drug survival in GCA.

Methods: Data were derived from an ongoing, multicenter, prospective cohort study of patients with GCA. During the 1st phase of the study, data regarding demographic and clinical characteristics at baseline, type of treatment, adverse events of therapy and co-morbidities were retrospectively collected and analyzed. Predictors of drug discontinuation were examined by univariate and multivariate logistic regression analyses.

Results: One hundred and seventy seven patients were included in the study; $70 \% \quad(n=120)$ were women with a mean age at diagnosis of $74 \pm$ 8.4 years. Diagnosis was established by temporal artery biopsy in 127 patients $(72 \%)$, ultrasound of temporal arteries in 37 patients $(21 \%)$ and large vessel imaging in 10 patients $(6 \%)$. At diagnosis, the median ESR and CPR were $103 \mathrm{~mm} / \mathrm{h}$ and $63 \mathrm{mg} / \mathrm{L}$, respectively. All patients were treated initially with pos corticosteroids (median daily starting dose: 41 $\mathrm{mg}$ ), while $12(7 \%)$ of patients received pulse steroids. At the 1st patient evaluation (median follow-up from diagnosis: 3 years), the median daily steroid dose was $5 \mathrm{mg}$, while in $34 \%(n=62)$ and $8 \%(n=14)$ of patients a synthetic or biologic DMARD had been added, respectively. During that period, $24 \%(n=43)$ of patients had discontinued corticosteroids and $18 \%(n=32)$ all treatments. By univariate analysis, DMARD use was associated with a higher possibility for corticosteroid discontinuation $(\mathrm{OR}=2.3, \quad \mathrm{p}=0.017)$ but by multivariate logistic regression analysis only female sex (OR=0.49, $\mathrm{p}=0.07$ ) and age at diagnosis $(\mathrm{OR}=0.94, \mathrm{p}=0.01)$ were associated with a decreased risk for corticosteroid discontinuation. Similar results were found for discontinuation of all drugs [female sex $(\mathrm{OR}=0.4, \mathrm{p}=0.05)$ and age at diagnosis $(\mathrm{OR}=0.9, \mathrm{p}=0.046)]$.

Conclusion: In this large GCA cohort, only one out of four patients managed to discontinue corticosteroids and $20 \%$ all treatments $\sim 3$ years after diagnosis. Multivariate analysis revealed only female sex and age at diagnosis as independent factors for treatment discontinuation.

Acknowledgement: Supported by grants from the Greek Rheumatology Society and Professional Association of Rheumatologists.

Disclosure of Interests:

None declared

DOI: 10.1136/annrheumdis-2019-eular.6298
SAT0248

CLINICAL OUTCOMES OF PATIENTS WITH GIANT CELL ARTERITIS TREATED WITH TOCILIZUMAB IN REALWORLD CLINICAL PRACTICE

Sebastian Unizony ${ }^{1}$, Jinglan $\mathrm{Pei}^{2}$, Paris Sidiropoulos ${ }^{2}$, Jennie H. Best ${ }^{2}$, Christine Birchwood ${ }^{2}$, John H. Stone ${ }^{1} .{ }^{1}$ Massachusetts General Hospital, Harvard Medical School, Boston, United States of America; ${ }^{2}$ Genentech, Inc., South San Francisco, United States of America

Background: Previously, the GiACTA study demonstrated the superiority of subcutaneous (SC) tocilizumab (TCZ) plus prednisone vs prednisone alone in achieving sustained glucocorticoid (GC)-free remission in patients with giant cell arteritis (GCA). ${ }^{1}$

Objectives: To evaluate the effectiveness and safety of SC and intravenous TCZ in real-world clinical practice.

Methods: We performed a retrospective analysis of GCA patients treated with TCZ at a single center (MGH) between 2010-2018. Annual relapse rate, time to disease relapse, number of relapses, prednisone use, and adverse events (AE) before and after TCZ initiation were assessed. Disease relapse was defined as the re-appearance of clinical manifestations of GCA (e.g., cranial symptoms) that required treatment modification.

Results: A total of 60 GCA patients were included in the analysis. Table 1 depicts the baseline characteristics and the treatments received by this cohort. The median (IQR) disease duration before TCZ use was $0.6(0.2$ 1.6) years. Fifty-eight patients $(96.7 \%)$ received concomitant prednisone (mean [SD] dose: 30 [18.3] $\mathrm{mg}$ daily) at the time of TCZ initiation. Patients received TCZ for a median (IQR) period of 0.5 (0.3-1.4) years. Before TCZ treatment, 43 patients $(71.7 \%)$ had $\geq 1$ relapse (median [IQR] time to relapse 0.5 [0.3-0.7] years). After TCZ initiation, 18 patients $(30.0 \%)$ had $>1$ relapse (estimated median [IQR] time to relapse 2.1 [0.6-2.3] years). The annual rate of relapse was lower on TCZ than while off TCZ (RR=0.40 $[95 \% \mathrm{Cl}, 0.25-0.63] ; \quad P=0.0001)$ (Table 2). Twentyseven patients $(46.6 \%)$ successfully tapered off prednisone during TCZ treatment. The incidence of $\mathrm{AEs}$ and serious $\mathrm{AES}$ (SAE) was similar before and after TCZ initiation (Table 2). During TCZ treatment, however, 38 of $81 \mathrm{AEs}$ were considered related or possibly related to prednisone. An AE led to TCZ discontinuation in 5 patients. No deaths occurred during the study period.

Conclusion: In this retrospective analysis, TCZ improved clinical outcomes in patients with GCA as indicated by a reduced incidence of relapses and by the ability to discontinue prednisone. The occurrence of AEs and SAEs (many due to GC) did not differ substantially while patients were on or off TCZ. These real-world findings support the previously reported efficacy and safety profile of TCZ in patients with GCA.

\section{REFERENCE}

[1] Stone JH, et al. N Engl J Med. 2017;377(4):317-328.

Table 1.. Patient baseline characteristics and treatments

\begin{tabular}{|c|c|}
\hline & $\begin{array}{c}\text { Total Patients } \\
\quad(\mathrm{N}=60)\end{array}$ \\
\hline Age, mean (SD) & $69.4(9.4)$ \\
\hline Female sex, n (\%) & $43(71.7)$ \\
\hline Caucasian ethnicity, $\mathrm{n}(\%)$ & $53(88.3)$ \\
\hline \multicolumn{2}{|l|}{ Clinical manifestations at disease onset } \\
\hline Headache, n (\%) & $47(78.3)$ \\
\hline Scalp tenderness, n (\%) & $26(43.3)$ \\
\hline Jaw claudication, $\mathrm{n}(\%)$ & $31(51.7)$ \\
\hline Amaurosis fugax, $\mathrm{n}(\%)$ & $11(18.3)$ \\
\hline Transient blurry vision, $\mathrm{n}(\%)$ & $18(30.0)$ \\
\hline Diplopia, n (\%) & $2(3.3)$ \\
\hline PMR symptoms, n (\%) & $32(53.3)$ \\
\hline ESR $(\mathrm{mm} / \mathrm{hr})$, mean $(\mathrm{SD})$ & $72.6(33.6)$ \\
\hline $\mathrm{CRP}(\mathrm{mg} / \mathrm{L})$, mean (SD) & $76.1(72.6)$ \\
\hline Positive TA biopsy, n (\%) & $26(43.3)$ \\
\hline Prednisone dose (mg/day) at disease onset, mean (SD) & $54(19.0)$ \\
\hline Use of other immunosuppressants before TCZ initiation, $\mathrm{n}(\%)^{*}$ & $15(25)$ \\
\hline Duration of disease before TCZ initiation (years), median (IQR) & $0.6(0.2-1.6)$ \\
\hline Prednisone dose (mg/day) at TCZ initiation, mean (SD) & $30(18.3)$ \\
\hline Received TCZ IV, n (\%) ${ }^{\dagger}$ & $22(37.3)$ \\
\hline Received TCZ SC, $\mathrm{n}(\%)^{\dagger}$ & $43(72.9)$ \\
\hline Duration of TCZ treatment (years), mean (SD) & $0.9(1.0)$ \\
\hline Duration of TCZ treatment (years), median (IQR) & $0.5(0.3-1.4)$ \\
\hline
\end{tabular}

polymyalgia rheumatica; $S C$, subcutaneous; TA, temporal artery; TCZ, tocilizumab. 